\title{
The Adequacy of the Structure of the National Library of Medicine Classification Scheme for Organizing Pharmacy Literature
}

\section{Elsa M. López-Mertz}

\begin{abstract}
The National Library of Medicine Classification (NLMC) scheme was developed in 1946, using basic ideas from earlier schemes developed for organizing resources in support of teaching medicine and widely used in the United States for classifying information resources including pharmacy and pharmaceutics. The purpose of this study is to examine how the structure of the NLMC accommodates pharmaceutical literature and assess its adequacy. The author analyzed the NLMC numbers assigned to 1,979 monographs with bibliographic records. The analysis revealed that the structure of the NLMC brought together $42 \%$ of the literature in the sub-class QV 701-835 while another $41 \%$ was scattered throughout the NLMC scheme. Additionally, 17\% was classified elsewhere in the Library of Congress Classification (LCC).
\end{abstract}

$\mathbf{I}$

Jibrary classifications group documents together through a system of classes arranged in some principle, purpose, or interest (Young 1983). In 1943, the Survey Report on the Army Medical Library, which is now the National Library of Medicine (NLM), recommended the reclassification of the library collection using a modern scheme (Army Medical Library 1948). With this recommendation in mind, the National Library of Medicine Classification (NLMC) was developed. The preliminary edition was published in 1948 and the first edition in 1951.

The NLMC was the most important research activity related to medical classi- fication (Bloomquist 1959). By the 1970s, the trend was clearly one of acceptance of the NLMC as the universal classification scheme for organizing U.S. medical library collections (Hines 1974). Users perceived greater browsability and in some libraries, faculty members recommended the use of NLMC over the older medical classifications. Together with the lack of maintenance of older classifications and the availability of cataloging records nationally in CATLINE or other databases, most libraries associated with teaching of medicine or specializing in other health science professions adopted the NLMC (Scheerer and Hines 1974).

ELSA M. LOPEZ-MERTZ (elopez@upracd.upr.cou.edu) is Assistant Professor at the Graduate School of Library and Information Science, University of Puerto Rico, Box 21906, University Station, San Juan, Puerto Rico 00931-1906. The author thanks Dr. Doris Clack, Professor, Florida State University, for her unflagging guidance and encouragement. Manuscript received July 8, 1996; accepted for publication February 21, 1997. 
Since its initial development, the classification scheme has been under continuous revision. At the time when this study was conducted, the Cataloging Division of the NLM was working on the 5 th edition of the NLMC, since published late in 1994. Today it is the only up-to-date classification scheme in the United States especially designed for the organization of health sciences literature.

The NLMC is divided into two major parts, which are further divided into 41 main headings. Part I, Preclinical Sciences (QS-QZ), is subdivided into eight main topics, of which the class Pharmacology (QV) is one. Pharmacy and Pharmaceutics is a separate topic in Pharmacology. Part II, Medicine and Related Subjects (W), is subdivided into topics that are arranged hierarchically from general to specific. Beginning with class W Medical Profession, the W class continues through two-letter subdivisions to end with History of Medicine (WZ). A special schedule exists for classifying books published in the 19th century.

Three classification systems were codified specifically for pharmaceutical literature: one by the Eli Lilly Company in 1915 , a second one by the Massachusetts College of Pharmacy in 1916, and a third one by the University of Cincinnati (no date available). There is no evidence that any of these classification schemes have been kept up-to-date. Therefore, this study is limited to the NLMC as it is the only up-to-date classification scheme generally used in the United States for the organization of health sciences literature. The purpose of the study is to examine how the structure of the NLMC accommodates pharmaceutical literature, to determine its adequacy, and to provide information on the development of this scheme.

\section{The Problem}

Fundamentally, the NLMC was developed using basic ideas from Cunningham (1937), a classification scheme developed from the viewpoint of teaching medicine. A team of experts developed the NLMC with representation from many-but not all $\rightarrow$ of the health science professions. The principal focus of the scheme was medicine, and the original team of experts included representatives from most of the medical specialties, public health, and the basic sciences. There were consultants from the field of nursing, dentistry, geography, and clinical psychology (Army Medical Library 1948). No one represented the field of pharmacy.

The NLMC was designed for use in conjunction with the Library of Congress Classification (LCC) and does not include non-medical subjects in its scope. The NLMC classes QS-QZ and W are not used by the LCC (nor does the NLMC use classes Q-QP used by LCC), allowing the $N L M C$ to develop specificity in the areas of its coverage. The NLMC was designed basically as a broad classification intended to be suitable for both large and small library collections, as well as be adaptable for specialized collections. However, the economics of making local adaptations precludes much activity in this area. The need for research remains because few changes have been made in the NLMC pharmacy subclass while the discipline has changed considerably. And the NLM welcomes suggestions made by researchers in other disciplines.

The study is based in the following research questions:

1. To what extent does the structure of the NLMC accommodate published pharmacy literature?

a. What are the fundamental categories of published pharmacy literature?

b. What are the fundamental categories provided in the $N L M C$ for pharmacy literature?

c. To what extent are the fundamental categories of the NLMC and those of the body pharmacy literature congruent?

2. To what extent is the NLMC adequate for organizing pharmacy literature?

a. To what extent is the pharmacy literature brought together as a logically organized body of literature by the NLMC?

b. How logical are the arrays in the 
NLMC with regard to pharmacy literature?

c. To what extent is the pharmacy literature scattered in the NLMC?

d. To what extent are the logical arrays in the $N L M C$ congruent with those of the published body of literature?

Others have reported on the adequacy of $N L M C$ in the areas of dentistry, psychiatry, and clinical nursing (e.g., Strauss 1973; Fernando 1984; Caffarel 1978). Strauss identified 29 subjects needed to provide greater specificity in the dentistry class (WU) with 5 subjects later included in the NLMC fourth edition. Caffarel pointed out that 9 clinical nursing specialities were included in one notation (WY 150 ) with other clinical nursing specialities classified in other notations, which hindered browsability. Again, most of Caffarel's recommendations were implemented in the following edition of the $N L M C$. Fernando suggested both the expansion of the Psychiatry class (WM) and the incorporation of modern terminology of psychiatry into the NLMC. A structural overview and examination of the relationship of the NLMC to the Medical Subject Headings (MeSH) was done by Cochrane (1989). To date, no other studies have investigated the adequacy of the NLMC with regard to the organization of pharmacy and pharmaceutical titles.

\section{METHODOLOGY}

The titles used in the study were selected from the bibliographies published by the American Association of Colleges of Pharmacy (AACP) and the Medical Library Association (MLA) between 1955 and 1989 (Medical Library Association Committee on Standards 1955; Zachert and Thomasson 1963; Jackson 1969a \& 1969b; Piermatti, Hills, and Snow 1983 and 1986; and Snow 1989). These bibliographies have been used as basic tools in the building of pharmaceutical collections in academic libraries. These bibliographies were compiled by librarians working in colleges of pharmacy from surveys of the faculty members and other people interested in the field. They represent the rec- ommended resources necessary to support the pharmacy discipline. All six were included in the study to ensure the inclusion of titles in all subject areas pertaining to pharmacy.

Using the computer program ProCite, the six bibliographies were merged into a database (Asklepios) containing 3,264 records. A record was created for the latest edition of each title with a note when more than one edition existed. All titles were then searched in CATLINE to obtain the NLM classification number. CATLINE was selected as the source database because the NLMC numbers on these records are assigned only by NLM catalogers, who are also responsible for keeping NLMC current. They are knowledgeable in the use of the system and some level of intercataloger consistency is therefore assumed.

Of the 3,264 records in the Asklepios database, 2,208 $(68 \%)$ were found in CATLINE. From these, serial titles were eliminated, as the classification number is in part based on format. Also, foreignlanguage titles, which are peripheral to the NLM collection emphasis on biomedical literature (including pharmacy), are by policy not classified and those records were eliminated (National Library of Medicine 1993). The final study population included 1,979 bibliographic titles (60\% of the 3,264 Asklepios records).

\section{Pharmacy Literature in the NLMC}

Through the call numbers assigned to the records analyzed in the study, five distinct subject groupings in the NLMC were identified. For this research, these groups were viewed as the fundamental categories of pharmacy in the NLMC as determined by the published literature: Group 1, Pharmacology; Group 2, Pre-clinical Sciences other than Pharmacology; Group 3, Medicine and related subjects; Group 4, Bibliographies; and Group 5, Subjects classified in LCC (see table 1).

From the 1,979 records used in this study, 838 titles $(42 \%)$ were classified in Group I: Pharmacology. Class QV Pharmacology includes three subclasses: $\mathrm{QV}$ 
126/LRTS • 41(2) • López-Mertz

TABLE 1

DistRibution OF TITLES CLASSED IN NLMC

\begin{tabular}{|c|c|c|}
\hline Class Number & Subject & No. of Titles \\
\hline \multicolumn{3}{|c|}{ Group I: Pharmacology } \\
\hline QV & 19th Century & 007 \\
\hline QV $1-370$ & Pharmacology & 496 \\
\hline QV 600-667 & Toxicology & 041 \\
\hline QV 701-835 & Pharmacy and Pharmaceutics & 294 \\
\hline Total titles in Group 1: & & 838 \\
\hline \multicolumn{3}{|c|}{ Group 2: Preclinical Sciences (other than Pharmacology) } \\
\hline QS & Human Anatomy & 021 \\
\hline QT & Physiology & 015 \\
\hline QU & Biochemistry & 125 \\
\hline QW & Microbiology and Immunology & 024 \\
\hline QX & Parasitology & 001 \\
\hline QY & Clinical Pathology & 022 \\
\hline QZ & Pathology & 037 \\
\hline Total titles in Group 2: & & 245 \\
\hline \multicolumn{3}{|c|}{ Group 3: Medicine and Related Subject } \\
\hline W & Medical Profession & 45 \\
\hline WA & Public Health & 68 \\
\hline WB & Practice of Medicine & 37 \\
\hline WC & Infectious Diseases & 07 \\
\hline WD & $\begin{array}{c}\text { Deficiency Disease ... Aviation and } \\
\text { Space Medicine }\end{array}$ & 34 \\
\hline WE & Musculoskeletal System & 05 \\
\hline WF & Respiratory System & 04 \\
\hline WG & Cardiovascular System & 10 \\
\hline WH & Hemic and Lymphatic System & 08 \\
\hline WI & Gastrointestinal System & 11 \\
\hline WJ & Urogenital System & 03 \\
\hline WK & Endocrine System & 34 \\
\hline WL & Nervous System & 26 \\
\hline WM & Psychiatry & 46 \\
\hline $\mathrm{WN}$ & Radiology & 45 \\
\hline WO & Surgery & 09 \\
\hline WP & Gynecology & 04 \\
\hline WQ & Obstetrics & 11 \\
\hline WR & Dermatology & 14 \\
\hline WS & Pediatrics & 09 \\
\hline
\end{tabular}


TABLE 1 (cont.)

\begin{tabular}{|c|c|c|}
\hline Class Number & Subject & No. of Titles \\
\hline WT & Geriatrics. Chronic Disease & 19 \\
\hline WU & Dentistry. Oral Surgery & 01 \\
\hline WV & Otorhinolaryngology & 01 \\
\hline WW & Ophthalmology & 10 \\
\hline WX & $\begin{array}{l}\text { Hospitals and Other Health } \\
\text { Facilities }\end{array}$ & 20 \\
\hline WY & Nursing & 04 \\
\hline WZ & History of Medicine & 30 \\
\hline \multicolumn{2}{|l|}{ Total titles in Group 3: } & 515 \\
\hline \multicolumn{3}{|c|}{ Group 4: Bibliographies } \\
\hline ZQV $1-370$ & General Pharmacology & 11 \\
\hline ZQV 600-667 & Toxicology & 01 \\
\hline ZQV 701-835 & Pharmacy and Pharmaceutics & 16 \\
\hline $\mathrm{ZQZ}$ & Pathology & 01 \\
\hline ZSF & Veterinary Medicine & 01 \\
\hline ZW-ZWZ & $\begin{array}{l}\text { Medical Profession... } \\
\text { History of Medicine }\end{array}$ & 11 \\
\hline Total titles in Group 4: & & 41 \\
\hline \multicolumn{3}{|c|}{ Group 5: Library of Congress Classification } \\
\hline G-P & $\begin{array}{c}\text { Geography ... Language } \\
\text { and Literature }\end{array}$ & 015 \\
\hline Q & Science & 235 \\
\hline$S$ & Agriculture & 041 \\
\hline $\mathbf{T}$ & Technology & 031 \\
\hline $\mathbf{U}$ & Military Medicine & 001 \\
\hline $\mathbf{Z}$ & Bibliography. Library Science & 018 \\
\hline Total titles in Group 5 : & & 340 \\
\hline Total number of titles & & 1,929 \\
\hline
\end{tabular}

1-370 General Pharmacology, consisting of 496 titles ( $60 \%$ of the 838 titles); QV 600-667 Toxicology, consisting of 41 titles (5\%); and QV 701-835 Pharmacy and Pharmaceutics, consisting of 294 titles (35\%).

Works pertaining to pharmacy are in the Pharmacology class although the placement under subclass varies. Literature about the pharmacist is located under Pharmacy as a Profession in the form number QV 21, the subclass General Pharmacology, instead of QV 721, the subclass Pharmacy and Pharmaceutics. (In the NLM, the first 39 numbers of a class or subclass are form numbers, with some exceptions-one of which is seen in the QV 701-835 (Pharmacy and Pharmaceutics subclass), where the lack of form numbers puts the classification of pharmacists in QV21 instead of QV721.) "Pharmacist" and "pharmacologist" are different professional categories (there is no need to be a pharmacist to become a pharmacologist), yet in the NLMC 4th revised edition there is no separate space for the pharmacologist.

Also, literature about Education, Schools and Colleges, and Research in the field of pharmacy, is located under the form 
numbers for Pharmacology: QV 18, QV 19, QV 20, and QV 20.5; instead of QV 718, QV 719, QV 720, and QV 720.5 in the Pharmacy and Pharmaceutics subclass. Because not all form numbers are included under QV 701-835 Pharmacy and Pharmaceutics, works pertaining to the field of pharmacy are located under Pharmacology.

Two hundred and forty-five records (13\%) were classified in Group 2: Preclinical Sciences. From this total, 51\% were under Biochemistry (QU), $6 \%$ under Human Anatomy (QS), 9\% under Physiology (QT), 9\% under Clinical Pathology (QY); and 15\% under Pathology (QZ). Five hundred and fifteen records (26\%) were classified in Group 3: Medicine and Related Subjects. From this group 13\% of the records were classified in Public Health (WA); $9 \%$ were classified under Medical Profession (W), 9\% in Radiology (WN), 9\% under Psychiatry (WM), and $7 \%$ in the Practice of Medicine (WB). Works about nuclear pharmacy are placed under Radiology (WN), and those about drug addiction and drug abuse are located under Psychiatry (WM). Books about drug therapy are classified in Therapeutics (WB). Books classified in other classes rank between $0.02 \%$ to $6 \%$. In the NLMC, works in the use and treatment of a particular disease are classified with the disease; for example, works in the anatomy, histology, embryology, physiology, and biochemistry of a part of the body are classified with the body part instead of placing them under the general class or sub-class for these topics (National Library of Medicine 1981). Works on vitamins are classified in Biochemistry (QU), and works on endocrine preparations are located in classes Urology (WJ), Endocrinology (WK), and Gynecology (WP).

Group 4 includes bibliographies. All those bibliographies classified within the scope of the NLM take the class number from the subject, prefixed by a capital Z (National Library of Medicine 1981). 41 titles (2\%) were classified in Group 4: Bibliographies. Of this total, 16 titles $(39 \%)$ were classified in Pharmacy and Pharmaceutics (ZQV 701-835). Eleven titles $(27 \%)$ in Pharmacology (ZQV 1-370).
The remaining $34 \%$ were classified under $\mathrm{Z}$ following the instructions in the NLMC for the classification of bibliographies. Group V includes materials classed using LCC. It contained 341 records (17\%). Two hundred and thirty-five (69\%) were classified in Science (Q). There is a very close relationship between the field of chemistry and the field of pharmacy, so it is logical that any pharmacy collection would include a large number of books from the field of chemistry. Forty-one $(12 \%)$ were in Agriculture (S), 31 titles (10\%) in Technology (T), 17 titles (6\%) in Bibliography, Library Science (Z), and 11 titles (3\%) were in Social Science $(\mathrm{H})$. The remaining 5 titles were in Geography (G), Political Science (J), Law $(\mathrm{K})$, Language and Literature $(\mathrm{P})$, and Military Medicine (U).

\section{Classification by Pharmacy Curricula}

For this study, the universe of knowledge has been defined as pharmacy. The subjects taught in schools of pharmacy served as the basis for a model classification of the pharmacy literature, against which the NLMC's organization of the pharmacy literature was compared. The extent of the structural adequacy of the NLMC for organizing pharmacy was determined by the extent to which the NLMC was congruent with the model developed from subjects taught in the schools of pharmacy.

The Roster of faculty and paraprofessional staff (AACP 1992-93) was the source used to identify subjects taught in pharmacy, which are listed below in the topical order used in the reports on pharmaceutical curricula published in 1952 and 1967, those of current bulletins of U.S. pharmacy schools, and the definition given by the National Association of Boards of Pharmacy about the practice of pharmacy. The Roster identifies nine academic disciplines, most of them divided into different subjects:

1. Libraries and Educational Resources

2. Liberal Arts

3. Biological Sciences: Anatomy, Histology, Physiology, and Pathology

4. Medicinal and Pharmaceutical 
Chemistry: Pharmacognosy, Biochemistry, Biomedical chemistry, Inorganic pharmaceutical chemistry, Molecular and quantum biology, Natural product chemistry, Pharmaceutical analysis, and Physical and medicinal chemistry

5. Pharmacology: Clinical pharmacology, Molecular pharmacology, and Toxicology

6. Pharmaceutics and Pharmacy: Agricultural pharmacy, Animal health pharmacy, Biopharmaceutics, Cosmetic science, Industrial pharmacy, Manufacturing pharmacy, Pharmacokinetics, Physical pharmacy, Veterinary pharmacy, and Veterinary science

7. Pharmacy Administration: Communication, Health care administration, Institutional and community pharmacy, Marketing, Pharmaceutical economics, Pharmacy accounting, Pharmacy jurisprudence, and Socialbehavioral pharmacy

8. Pharmacy Practice: Clinical pharmacy, Community practice, Drug information, Institutional practice, Nuclear pharmacy and radiopharmacy, Pharmacy ethics, and Pharmacy history.

9. Continuing Professional Education

These subjects were verified in the alphabetical list of the NLMC and assigned the appropriate classification notation. The 1993 edition of MeSH and the MeSH Tree Structure were used for assistance in this process. The purpose for assigning classification notations to the list of academic disciplines and their specific subjects was to enable a comparison between the AAAP list of subjects and those in the $N L M C$. This made it possible to determine how adequately the structure of the NLMC accomodates the subjects found in AAAP. Where the subjects could not be found in the $N L M C$, the subjects were searched as keywords in CATLINE to determine what titles were retrievable under those subjects and where they were classified in the NLMC.

From this work, the following mapping was constructed to show where individual titles in the 9 subjects (academic disciplines) of the AACP were classified in the NLMC (see table 2).
An examination of the 1,979 titles analyzed in the study reveals that 28 titles $(1.4 \%)$ supported the Libraries and Educational resources category. The Liberal Arts category provides the general educational background needed by the future pharmacist, including the courses from the natural sciences. Sixteen percent (308 titles) fell in this category. Nearly half of these were on chemistry. The Biological Sciences category provides the basic knowledge needed by the pharmacist to understand the action of drugs in the body. Eleven percent (209 titles) fell in this category. Two hundred titles $(10 \%)$ were in the Medicinal and Pharmaceutical Chemistry category; 358 titles (18\%) were in the Pharmacology category; 111 titles (6\%) were in Pharmaceutics and Pharmacy; 191 titles (10\%) were in Pharmacy Administration; and 504 titles (25\%) were in Pharmacy Practice. Seven titles $(0.003 \%)$ fell in the Continuing Professional Education category. This category includes books classified in Graduate and continuing education in pharmacy $(\mathrm{QV}$ 18) and Schools and colleges (QV 19). Eight percent (165 titles) did not fall into any of the categories, and were located under a miscellaneous category. This category included general titles that do not support a specific discipline.

\section{Summary AND Conclusions}

This study inaugurates research examining where the literature on pharmacy and pharmaceutics is classified in the NLMC. An analysis of this classification system was made to determine whether it adequately accommodates the body of literature relating to the pharmacy field, and if the NLMC organizes it adequately. Using as the frame the academic disciplines identified in pharmaceutical curricula, 10 fundamental categories were established that cover all the published pharmacy literature. Five of these categories were identified in the NLMC for the classification of pharmacy literature. According to the classification notation assigned to the titles supporting each subject in each of the pharmacy disciplines, a comparison 
TABLE 2

NLMC NUMBERS ASSIGNED TO TITLES IN AACP SUBJECTS

Call Number

QV 18-19, Z

G, H, J, K, P, Q, Z, T, QW, QX

QS 1-132, WE, WG, WH, WI,

WJ, WK, WL, WP, WV

QS 504-539, WL

QT, WE, WF, WG, WH, WI, WJ, WK, WL,

WP, WQ, WR, WS, WV

QY, QZ, ZQZ

QV 744

QV 752

QU

QU

QV 744

QV 744, 752, 766-770.1

QV 744

QV 744

QV $1-370$

QV 38

QV 38

QV 600-667, WD 400, WD 500, ZQV

QV 701-835

S, SB

QV 38

QT 275, WA 744, TP

QV 736, HD 9665, T 55

QV 736, 771, 773

QV 38

QV 736

SF

SF, ZSF

QV 704, W 275

QV 21

W, WA, WS 29 , WT 30 , WX

QV 737, WX 179

QV 736

QV 704, TP

QV 736

QV 736
Subjects from AACP

Libraries and Educational Services

Liberal Arts

Biological Sciences

Anatomy

Histology

Physiology

Pathology

Medicinal and Pharmaceutical Chemistry

Pharmacognosy

Biochemistry

Biomedical Chemistry

Inorganic Pharmaceutical Chemistry

Molecular and Quantum Biology

Natural Product Chemistry

Pharmaceutical Analysis

Physical and Medicinal Chemistry

Pharmacology

Clinical Pharmacology

Molecular Pharmacology

Toxicology

Pharmaceutics/Pharmacy

Agricultural Pharmacy

Animal Health Pharmacy

Biopharmaceutics

Cosmetic Science

Industrial Pharmacy

Manufacturing Pharmacy

Pharmacokinetics

Physical Pharmacy

Veterinary Pharmacy

Veterinary Science

Pharmacy Administration

Communication

Health Care Administration

Institutional and Community Pharmacy

Marketing

Pharmaceutical Economics

Pharmaceutical Socioeconomics

Pharmacy Accounting 
TABLE 2 (cont.)

\begin{tabular}{lc}
\hline Call Number & Subjects from AACP \\
\hline QV 32-33.1 & $\begin{array}{c}\text { Pharmacy Jurisprudence } \\
\text { Social and Behavioral Pharmacy }\end{array}$ \\
QV 13-26, QV 701-835 & Pharmacy Practice \\
QV 5, 38, 39, QV 704, WB 330, & Clinical Pharmacy \\
WX 179 & \\
QV 737 & Community Pharmacy \\
HV, WD 320, WM 270-276, & Drug Information \\
WM 286-88, WM 404 & \\
QV 20, WX 179 & Institutional Practice \\
WN & Nuclear Pharmacy/Radiopharmacy \\
QV 21 & Pharmacy Ethics \\
QV 711-11.1 & Pharmacy History \\
WB 330, 340, 342, 354, WW 166 & Therapeutics \\
QV 19-20 & Continuing Professional Education \\
\hline
\end{tabular}

between the fundamental categories in the $N L M C$ for the pharmacy field and in the fundamental categories of the published pharmacy literature shows this correlation:

Forty-two percent of the titles have been brought together by the structure of the NLMC under Pharmacology (QV); $41 \%$ are scattered throughout the $N L M C$; and $17 \%$ are under the LCC. General works supporting the Biological Sciences were classified in the Preclinical Sciences. The works on anatomy, histology, and physiology of a part of the body were classified with the part of the body as stated in the NLMC. Most of the works supported the five core disciplines in the field of pharmacy: Medicinal and Pharmaceutical Chemistry, Pharmacology, Pharmacy Administration, Pharmacy Practice were classified scattered through the NLMC. Few sources were classified under the LCC call numbers. The main problem is that the works supporting specific topics from the field of pharmacy were classified far away from the sub-table QV 701-835. For example, the works on Clinical Pharmacy, one of the most important topics in the field today, were classified under WB 330. The works on the Practice of Pharmacy were split; some of them were in WX 179, while others were in QV736.
The original subclass developed in the NLMC (preliminary edition) for the organization of pharmacy literature was separated from the Pharmacology class. So pharmacy and pharmacology were recognized as different fields. According to the NLMC 4th revised edition, class QV could be interpreted as Pharmacy or as the Practice of Pharmacology. Pharmacology is an important basic science for all health science professionals, but each area studies it for different purposes. For example, nurses need to know pharmacology because they administer drugs, while pharmacists study it to license drugs. Haddad $(1995,3)$ defined pharmacy as "the art and science of preparing and dispensing medications and the provision of drug and related information to the public. It involves the interpretation of prescription orders; the compounding, labeling, and dispensing of drugs and devices; drug product selection and drug utilization reviews; the responsibility for patient monitoring and intervention and the provision of cognitive services." According to the definition of pharmacy, professionals in this field have responsibilities that can be performed only by those licensed in pharmacy.

The current structure in the NLMC identifies Pharmacology as the class and Pharmacy and Pharmaceutics as one subclass under Pharmacology. According to 
TABLE 3

Comparison of CATEgories

\begin{tabular}{lc}
\hline $\begin{array}{l}\text { Fundamental Categories in the Published } \\
\text { Pharmaceutical Literature }\end{array}$ & $\begin{array}{c}\text { Fundamental Categories in } \\
\text { the NLMC for Pharmacy }\end{array}$ \\
\hline Pharmacology (QV 1-835) & Libraries/Educational Resources \\
Pharmaceutical/Medicinal Chemistry & Pharmacology \\
& Pharmaceutics \\
& Pharmacy Administration \\
& Pharmacy Practice \\
Preclinical Sciences (QS-QU, QW-QZ) & Continuing Professional Education \\
& Liberal Arts \\
& Biological Sciences \\
Medicine/Related Subjects & Pharmaceutical Medicinal Chemistry \\
(W-WB, WE-WL, WP-WQ) & Biological Sciences \\
& Pharmacology \\
& Pharmaceutics \\
& Pharmacy Administration \\
Subjects from LCC (A-QL, S-Z) & Pharmacy Practice \\
& Miscellaneous \\
& Biological Sciences \\
& Pharmacology \\
& Pharmaceutics \\
& Pharmacy Administration \\
& Pharmacy Practice \\
& Liberal Arts \\
& Miscellaneous \\
& \\
& \\
& \\
& \\
&
\end{tabular}

the definition of the pharmacy profession and the topics in the pharmacy curricula, Pharmacology is one of the subjects of Pharmacy as a universe of knowledge. Pharmacy, then, should be viewed in a different position, as the class Pharmaceutics and Pharmacology as a subclass under Pharmaceutics. Pharmacy should have the same place that other health science professions have-with pharmacology as a basic science for all of them.

The ideal structure of a classification system for Pharmacy should be one accommodating the literature on Medicinal and Pharmaceutical Chemistry, Pharmaceutics, Pharmacy Administration, and Pharmacy Practice as a whole-in proximity to Pharmacology as an important basic science. The analysis reveals that $58 \%$ of the literature is classified outside Pharmacology (QV). It might be concluded that the arrays in the NLMC are not logical for organizing literature for teaching pharmacy. The state of affairs is understandable, given that the NLMC was designed for teaching medicine, with pharmacy as a supporting discipline. Nevertheless, the structure renders the system problematic for organizing pharmacy literature for pharmacy library users. Pharmacy subjects are placed in the structure as they support pharmacology, a basic science in the teaching of medicine.

In summary, the structure of the NLMC does not accommodate pharmacypublished literature because the two sets 
TABLE 4

AACP AND NLMC Classification CATEgories

Fundamental Categories in the Published

Pharmaceutical Literature

Libraries/Educational Resources

Liberal Arts

Biological Sciences

Medicinal/Pharmaceutical Chemistry

Pharmacology

Pharmaceutics

Pharmacy Administration

Pharmacy Practice

Continuing Professional Education

Miscellaneous
Fundamental categories in the NLMC for Pharmacy

Subjects from the LCC (A-QL, S-Z)

Preclinical Sciences (QW)

Subjects from the LCC (A-QL, S-Z)

Preclinical Sciences (QS-QT, QY-QZ)

Pharmacology (QV 1-370, QV 744)

Preclinical sciences (QU)

Pharmacology (QV)

Medicine/related subjects (All those discussing drugs)

Bibliographies (ZQV)

Pharmacology (QV 701-835)

Medicine and Related Subjects (All those discussing therapeutics)

Bibliographies (ZQV)

Pharmacology (QV 21, QV 704)

Medicine and Related Subjects (W, WA)

Bibliographies (ZQV)

Pharmacology (QV 701-835)

Medicine and Related Subjects (W, WA)

Bibliographies

Pharmacology (QV 18-20.5)

Medicine and Related Subjects (W, WA)

Subjects from LCC (A-QL, S-Z) of fundamental categories are not congruent. The $N L M C$ is considered inadequate for organizing pharmacy literature because $58 \%$ of it is scattered to the NLMC or in the LCC. This has been the first study analyzing how the NLMC accommodates pharmacy literature. Additional research is needed to take a decision on improving subclass QV 701-835 or creating a new system for this body of knowledge. As Chan (1990) pointed out, the NLMC deserves serious study. Studies should be done in collaboration between classifiers and pharmacists, because classifiers are the experts in classification while pharmacists are the experts in Pharmacy.

\section{RECOMMENDATIONS}

The pharmacy field has evolved from a chemistry-oriented bachelor's degree program to a clinical pharmacy program with the advent of a clinical orientation to the profession. Since the 1960s, the strong emphasis in pharmacy schools has been toward the Doctor in Pharmacy degree and the clinical pharmacy programs. The clinical pharmacy program was created in response to medical reports on adverse drug reactions, drug-drug interactions, food-drug interactions, and medication errors in hospitals. The clinical pharmacist, then, became the drug specialist providing consultant services to the physicians who were overwhelmed by the large amount of information on drugs (Biles 1983).

Additional research is necessary to add to the body of knowledge regarding the organization of pharmaceutical literature and to provide a theoretical basis for improving access to information resources in 
this field. On the other side, the vocabulary used in a classification seheme facilitates access to the information. It is necessary that a research study be undertaken to analyze the currency, accuracy, and specificity of the vocabulary used in the NLMC, particularly in relation to pharmaceutical subjects. Professionals from the field of pharmacy believe that the vocabulary used in the NLMC is not representative from the field today (Adrover 1994; Pérez 1994; Redda 1994). The vocabulary from the pharmacy field needs to be analyzed and a thesaurus and database developed and coded to MeSH - the standard vocabulary used in the health sciences field.

There is no definitive body of knowledge that documents the organization, standards, and tools used in pharmacy libraries. A survey is needed to determine how pharmacy libraries organize their collections and how they use the NLMC or other specialized classification systems for information storage and retrieval of pharmacy literature. This information would determine the need for the development of a specialized classification, perhaps coded to the $N L M C$, for pharmacy libraries.

Studies in classification are important to increase the effectiveness of classification schemes. If there is no feedback from libraries using a specific classification scheme or is there is no research, the system could lose its efficiency. Also, though the NLMC is close to 50 years old and is the only major classification scheme in the United States specifically for the organization of the health sciences literature, very few studies have been reported in the literature. The NLMC deserves such research. There is no doubt that users will benefit and information services would be greatly improved.

Note: After this study was completed in 1994, the fifth edition of the NLMC was published and readers are encouraged to examine it. Class QV contains a few changes. In the subclass Pharmacy and Pharmaceutics, form numbers for Classification, Nomenclature, Terminology (QV715), Atlases and Pictorial Works (QV717) and Directories (QV722-711.2), and Jurisprudence (QV732-22.1) were added. QV 21 is now used to classify the works on Pharmacy as a Profession and Pharmacology as a Profession. A number for Materia medica (QV760) was also added. Although these changes resolve some problems pointed out in the study, others still need work.

\section{WORKS CITED}

Adrover, Alma. 1994. Interview. Caguas, P.R.: Jannsen Pharmaceuticals.

American Association of Colleges of Pharmacy. 1992. Roster of faculty and paraprofessional staff. Alexandria, Va.: AACP.

Army Medical Library. 1948. Army Medical Library classification: Medicine, Preliminary Ed. Washington, D.C.: Superintendent of Documents, U.S. Govt. Print. Off.

Biles, John. 1983. The doctor of pharmacy. Journal of the American Medical Association 249: 1157-60.

Bloomquist, Harold. 1959. Cataloging and classification of medical library materials: 1946-1956, ten years of progress and problems. Bulletin of the Medical Library Association 47; 144-64.

Caffarel, Agnes. 1978. Classification of clinical nursing texts: A new approach. Bulletin of the Medical Library Association 66:52-55.

Chan, Lois Mai, 1991. Immroth's guide to the Library of Congress Classification for medical literature, 4th rev. ed. Englewood, Colo.: Libraries Unlimited, Inc.

Cochrane, Pauline A. 1989. A description of the structure of the National Library of Medicine Classification. [Photocopy, $\mathrm{Na}-$ tional Library of Medicine.]

Cunningham, Eileen R. 1937. A classification for medical literature, 2nd. ed. Nashville, Tenn.: Cullom \& Ghertner Co.

Eli Lilly classification scheme. 1915(?). [Photocopy, Eli Lilly.]

Fernando, Suschila I. 1984. The classification of library materials in psychiatry at the Staff Library Porirua Psychiatric Hospital. New Zealand libraries 44: 109-13.

Haddad, Abraham J. 1995. Scope. In: Remington: The science and practice of pharmacy. Easton, Pa.: Mack Publishing Co.

Heath, Ethel. 1916. A system of classification for a pharmacy library. Bulletin of the Massachusetts College of Pharmacy 6: 13-24. 1926. A system of classification for a pharmacy library, 2nd ed. Bulletin of the Massachusetts College of Pharmacy 15: 3-43.

Hines, Lois E. 1973. A study of classification 
used in medical libraries with special attention to reclassification to NLM classification. Master's thesis, University of California, Los Angeles.

Jackson, Elizabeth Christian. 1969a. Books for pharmacy colleges, 1962-1968. Part I. American journal of pharmaceutical education 33:246-67.

$1969 \mathrm{~b}$. Books for pharmacy colleges, 1962-1968. Part II. American journal of pharmaceutical education 33: 411-58.

Jones, Irene. 1956. Classification. In: Handbook of medical library practice, $2 \mathrm{~d}$ ed., ed. Janet Doe and Mary Louise Marshall. Chicago: American Library Association.

Kamenoff, Lovisa. 1979. Classification of nursing texts in a hospital library. Bulletin of the Medical Library Association 67: 247-51.

López-Ramírez, Elsa María. 1994. The adequacy of the structure of the National Library of Medicine classification scheme for organizing pharmacy literature. Ph.D. diss., Florida State University, Tallahassee, Florida.

Marshall, Mary Louise, and Irene Jones. 1943. Classification. In Handbook of medical library practice, ed. Janet Doe and a Committee of the Medical Library Association; based in a preliminary edition manuscript by $\mathrm{M}$. Irene Jones. Chicago: American Library Association.

Medical Library Association Committee on Standards and Criteria for Pharmacy School Libraries. 1955. Books, reference work and periodical literature for colleges of pharmacy libraries. American journal of pharmaceutical education 19: 480-99.

Meyn, M. Faye, and Marilee M. Thome. 1978. A new method of classifying clinical nursing monographs. Bulletin of the Medical Library Association 66: 460-61.

National Library of Medicine Associate Program. 1988-89. Bibliographic control module. [Photocopy, National Library of Medicine.]

National Library of Medicine. 1993. Collection development manual of the National Library of Medicine, 3rd. ed. Bethesda, MD: U.S. Department of Health and Human Services. Public Health Service. National Institute of Health.

- 1981. National Library of Medicine classification: A scheme for the shelf arrangement of books in the field of medicine and its related sciences, 4 th rev. ed. Be- thesda, Md.: U.S. Department of Health and Human Services. Public Health Service. National Institute of Health.

Pérez, Angela. 1994. Interview. San Juan, P.R.: University of Puerto Rico, School of Pharmacy.

Piermatti, Patricia A., Barbara M. Hills, and Bonnie Snow. 1983. A basic book list for pharmaceutical education. Alexandria, Va.: American Association of Colleges of Pharmacy.

-_ 1986. A basic book list and core journals for pharmaceutical education. Alexandria, Va.: American Association of Colleges of Pharmacy.

Redda, Kinfe Kent. 1994. Interview. Tallahassee, Fla.: Florida Agricultural and Mechanical University, School of Pharmacy.

Scheerer, George, and Lois Hines. 1974. Classification systems used in medical libraries. Bulletin of the Medical Library Association 62: 273-80.

Snow, Bonnie. 1989. Drug information: $A$ guide to current resources. Chicago: Medical Library Association.

Strauss, Carol D. 1973. A suggested expansion of the NLM classification for dentistry. Bulletin of the Medical Library Association 61: 452-57.

Ugolini, Donatella, and others. 1990. The NLM classification scheme and a suggested expansion for oncology. Health information and libraries 6 , no. 3: 40-46.

Utt, Marjorie. 1939. Library classification in the biological sciences with special reference to systems used in medical libraries. Master Thesis, University of California.

Wessex Regional Library and Information Network. 1994. Wessex classification scheme, 2 d ed. Hampshire, England: University of Southampton.

Young, Heartsill, ed. 1983. The ALA glossary of library and information science. Chicago: American Library Association.

Zachert, Martha Jane K., and Larry Thomasson. 1963a. Bibliography of books and reference works relating to the professional courses in the pharmaceutical curriculum. Part I. American journal of pharmaceutical education 27:266-90.

1963b. Bibliography of books and reference works relating to the professional courses in the pharmaceutical curriculum. Part II. American journal of pharmaceutical education 27: 361-421. 